\title{
O SISTEMA DE PROTEÇÃO SOCIAL CHILENO: DA DITADURA MILITAR AOS DIAS ATUAIS
}

RAQUEL DE B. SOUSA ${ }^{1}$; FERNANDA A. R. PAZ ${ }^{2}$; JALDES R. DE MENESES ${ }^{3}$

${ }^{1}$ UFPB. Mestrado em Serviço Social. CV: http://lattes.cnpq.br/0903908330597475

${ }^{2}$ UFCG. Mestrado em Serviço Social. CV: http://lattes.cnpq.br/8498993023420115

${ }^{3}$ UFPB. Doutor em Serviço Social pela UFRJ. CV: http://lattes.cnpq.br/1670279752922926

Artigo submetido em Junho/2016 e aceito em Julho/2016

\section{RESUMO}

Este artigo se propõe a elucidar a proteção social no Chile, com enfoque nas políticas de saúde, previdência social e assistência social. Para isso, realizamos uma pesquisa bibliográfica a partir de autores como Ivanete Boschetti, Carmela Mesa-Lago, Rodrigo Castelo, Renata Baía Afonso Rego Alvim, Cláudia Robles e outros que são referências nessa discussão. Analisamos as informações mais importantes sobre a construção do sistema de proteção social e sua configuração na atualidade, a fim de conhecer a realidade do país, a forma que se desenvolveu historicamente e como se configura atualmente seu modelo de proteção social. Nossa análise possibilitou a apreensão do processo de contrarreforma que o sistema de proteção social chileno vem sofrendo desde a ditadura militar, mesmo considerando a ampliação dos investimentos após esse período.

PALAVRAS-CHAVE: Assistência Social. Chile. Previdência Social. Saúde.

\begin{abstract}
This article aims to elucidate the social protection in Chile, focusing on health policy, social security and social assistance. To this end, we conducted a literature search from authors like Ivanete Boschetti, Carmela Mesa-Lago, Castelo Rodrigo, Renata Rego Bay Afonso Alvim, Claudia Robles and others who are references in this discussion. We analyze the most important information about the construction of the social
\end{abstract}

protection system and its configuration today in order to know the reality of the country, so that has developed historically and how it currently sets its model of social protection. Our analysis led to the apprehension of contrarreforma process that the Chilean social protection system has been suffering since the military dictatorship, even considering the expansion of investments after this period.

Keywords: Social Assistance. Chile. Social Security. Social protection. Cheers. 


\section{INTRODUÇÃO}

O presente artigo tem como objetivo discutir a construção do sistema de proteção social $^{1}$ no Chile, fazendo uma retrospectiva da sua formação, dos rebatimentos sofridos no período ditatorial para o conjunto das políticas sociais que compõem o referido sistema, assim como sua configuração após a redemocratização do país. Para tanto, focamos nossa análise nas políticas sociais de saúde, previdência e assistência social.

Para construção deste trabalho, realizamos uma pesquisa bibliográfica a partir de estudiosos dessa temática, bem como utilizamos informações divulgadas pelo governo chileno, com o objetivo de compreender a formação do sistema de proteção social e sua conformação no contexto atual, fazendo uma mediação dessa construção com a realidade social do país.

Segundo Boschetti (2009, p. 172), os países da América Latina "de alguma forma, instituíram sistemas de seguridade social, a partir dos anos 20/30 do século XX", ainda que de forma heterogenia ${ }^{2}$, isso significou uma forma de proteção social a população desses países, mesmo que de modo restrito. Além disso, desde sua gênese, a seguridade social latino-americana desenvolve-se seguindo não somente a "lógica do seguro" social contributivo, mas também da "assistência" não contributiva.

Assim, a proteção social na América Latina, por seu contexto social, econômico e político, desenvolveu-se de forma $\operatorname{tardia}^{3}$ e diferente quando comparado com os modelos

\footnotetext{
1 "Os sistemas de proteção social surgem na Europa ocidental, no contexto da Revolução Industrial, mas ganham amplitude no segundo pós-guerra, sendo [...] o conjunto organizado, coerente, sistemático e planejado de políticas sociais que garantem a proteção social por meio de amplos direitos, bens e serviços sociais, nas áreas de emprego, saúde, previdência, habitação, assistência, educação" (BOSCHETTI, 2012, p. 756).

${ }^{2}$ A seguridade social "em todos os países em que se desenvolveu, mesmo considerando as diferenças das suas configurações - visto que não se instituí da mesma forma em todos os países - se estrutura com base na organização social do trabalho. Diante da incapacidade do modo de produção capitalista de assegurar trabalho para todos os trabalhadores, a seguridade social assume a função de garantir direitos derivados do trabalho para os trabalhadores que perderam momentaneamente ou permanentemente, sua capacidade laborativa" (BOSCHETTI, 2009, p. 175-176). No Brasil, a partir da Constituição Federal de 1988 são consideradas parte da seguridade social as políticas de saúde, previdência e assistência social. Mas, destaca-se que esta caracterização não é comum na América Latina, em muitos países o termo (seguridade social) é utilizado para tratar da previdência social.

${ }^{3}$ Essas primeiras formas de proteção social - vinculadas aos direitos trabalhistas - que chega na América Latina entre as décadas de 1920 e 1930, já existiam nos países de capitalismo avançado desde da década de 60 do século XIX, também fruto de diversas lutas e mobilizações populares, que entre outros fatores - como o crescimento econômico dos países centrais, as baixas taxas de desemprego (pleno emprego), e o avanço do socialismo - permitiram o desenvolvimento das políticas sociais e do que chamamos de Estado de Bem-Estar Social (BERING; BOSCHETI, 2011). O Estado de Bem-Estar Social foi efetivado apenas nos países de capitalismo avançado, principalmente europeus, mesmo não se desenvolvendo da mesma forma nos diversos países de capitalismo avançado, mas podemos caracterizá-lo de forma geral, como a implantação de leis e medidas para garantia de direitos trabalhistas e de políticas de proteção social, como previdência, saúde, educação, assistência social, entre outras. "Além disso, o Estado passava a controlar os setores estratégicos da economia (energia, comunicações, transportes, serviços públicos, etc.)" (MANZANO, 2013, p. 106).
}

Dialektiké, v. 1, 2016. p. 79-97 
dos países centrais ${ }^{4}$. Como afirmam Taipa e Henrique (1995, p. 67), a proteção social na latino-americana "historicamente apresentam deficiências, limitações e exclusões em relação ao acesso aos programas, população coberta e qualidade dos serviços oferecidos", não assegurando adequadamente sua população, principalmente os setores da sociedade com menor poder de pressão social e os mais pobres. Assim, a restrição na oferta, a dificuldade no acesso, a desigualdade na qualidade dos serviços prestados entre as zonas urbanas e rurais, a lógica contributiva para acesso, a fragmentação e a estratificação marcam a trajetória das políticas sociais nessa região.

$\mathrm{Na}$ área da saúde, há uma predileção pela medicina curativa centrada no modelo hospitalocêntrico, que secundarizava a atenção básica e preventiva. Destaca-se que houve um desenvolvimento da atenção básica nas décadas de 1960 e 1970, porém insuficiente frente a demanda. E existia, na maioria dos países, uma "diferença entre o atendimento prestado por estabelecimentos públicos aos filiados à previdência social e o restante da população" (TAIPA; HENRIQUE, 1995, p.67). Em relação a previdência, os Estados atuaram em geral como reguladores. A assistência social surge no âmbito da caridade, e depois passa a ser assumida pelo Estado como direito, mas continua tendo como alvo a população mais pobre. Na década de 1970, ampliam-se os programas sociais da assistência social, mesmo que ainda de forma tímida e com pequena cobertura (TAIPA; HENRIQUE, 1995).

Destaca-se que, apesar do panorama descrito, existem diferenças locais no desenvolvimento da proteção social nos diversos países do continente latino-americano. Esta investigação busca se debruçar nas particularidades do Chile, com foco nas políticas de saúde, previdência e assistência social, no período da ditadura militar e pósredemocratização.

\section{SISTEMA DE PROTEÇÃO SOCIAL NO CHILE: OS IMPACTOS DA DITADURA MILITAR}

O Chile, assim como o Brasil e a Argentina, foi um dos pioneiros a implementar as primeiras formas de proteção social na América Latina, que surge vinculada as políticas trabalhistas, uma característica comum aos três países, assegurando apenas uma pequena parcela da população. Pois, como explica Santos (2012), desde de sua constituição, o mercado de trabalho dos países latino-americanos é caracterizado por altos índices de desemprego, "inexpressividade e, em vários casos, ausência de regulação do trabalho; alta rotatividade nos postos de trabalho; subemprego; informalidade..." (SANTOS, 2012, p. 434).

A proteção social chilena tem como marco a ascensão de Arturo Alessandri ao governo, em 1920, que chega ao poder com propostas de reformas, representando as camadas médias e se comprometendo a enfrentar as oligarquias chilenas. Trata-se de uma conjuntura de efervescência política, marcada por uma série de protestos, greves e outras séries de movimentos populares.

Em 1921, Arturo Alessandri, conseguiu aprovar no senado uma de suas maiores propostas eleitorais, o código do trabalho, que consistia na consolidação dos direitos

\footnotetext{
${ }^{4}$ Neste texto destacamos como países centrais, os países com capitalismo avançado, principalmente Estados Unidos, Japão e alguns países da Europa.
}

Dialektiké, v. 1, 2016. p. 79-97 
trabalhistas no país, apesar de se conciliar com os setores oligárquicos para se manter no poder, as propostas reformistas incomodam as oligarquias, fazendo com que ele seja deposto do poder em 1924 por uma junta militar. Mas logo após, o seu governo foi restaurado, e ele consegue a provação de uma nova carta constitucional para o Chile, sancionada em 1925. É importante enfatizar que "toda a década de vinte está marcada por período de severa crise institucional e contínuos protestos" (CASTRO, 2006, p. 69).

Ressalta-se que o Chile marcado em sua história por intensa mobilização e pressão popular, segundo Tetelboin (2009 p. 181) "os setores dos trabalhadores e dos empobrecidos do sistema, vinculados com as camadas médias e intelectuais, expressaram-se prematuramente no espaço social, política e reivindicatório da sociedade chilena". Além disso, é o país que tem o primeiro presidente socialista eleito democraticamente no continente, Salvador Allende, em 1970.

Allende chega ao poder através da união da esquerda em uma chapa chamada Unidade Popular, e seu governo buscará dar continuidade a proposta de governos anteriores, com reformas estruturais no país, propondo alterações a longo prazo, que levariam o Chile ao modelo socialista. A pressão e organização popular, como supracitado, tornaram possível que entre os anos de 1958 e 1973, os governantes do Chile buscassem realizar reformas que fornecessem um caráter mais universal e menos fragmentado as políticas sociais.

Apesar desse governo não ter características radicais, implementou reformas que atacavam a burguesia ${ }^{5}$ chilena e internacional, em especial, a reforma agrária e estatização das empresas estrangeiras - majoritariamente norte-americanas - de exploração do cobre no país, provocando a insatisfação dos Estados Unidos, que passou a apoiar movimentos de oposição. Após essas medidas, o governo chileno sofrerá um boicote, tendo seus produtos recusados pelo mercado internacional, o que leva o país a uma grave crise econômica e altos índices inflacionais. Os Estados Unidos financiam um segmento de rebeldes contra o governo, gerando um estado de guerra civil.

O Chile até 1973, tem em sua sociedade "certa estabilidade política no seu modo de transcorrer política e economicamente tendo em vista a natureza do país subdesenvolvido e a história de outros países latino-americanos" (TETELBOIN, 2009, p. 181). Ou seja, apesar das diversas mobilizações populares, é um dos países com maior histórico republicano da América Latina. Mas em 1973 houve um golpe de Estado promovido pelas Forças Armadas contra o governo de Allende, sendo instaurada uma ditadura militar sob o comando do general Augusto Pinochet, também apoiado pelo governo dos Estados Unidos e pela camada conservadora chilena ${ }^{6}$. Assim começa a história do neoliberalismo ${ }^{7}$ na América Latina, que

\footnotetext{
5 “ Por burguesia entende-se a classe dos capitalistas modernos, proprietários dos meios de produção social que empregam o trabalho assalariado (MARX, ENGELS, 2014, p. 40)

${ }^{6}$ Inclui-se aqui a burguesia chilena, bem como camadas da população que apoiaram o golpe, como alguns setores das camadas médias.

7 Salienta-se, em meados de 1970, tem-se o esgotamento do modelo de produção capitalista fordistakeynesiano, assim o capitalismo internacional atravessa mais uma crise sistêmica. Com o objetivo de solucionar sua crise, o capitalismo passa por reestruturação, com destaque a mundialização do capital, que é acompanhado por um processo de reestruturação produtiva e econômica e, consequentemente uma nova forma de intervenção estatal, para ajustar os Estados às novas demandas econômicas e ideopolíticas, o último conhecido como neoliberalismo.
}

Dialektiké, v. 1, 2016. p. 79-97 
tem início com o golpe do general Augusto Pinochet, que tem como objetivo implementar no país o receituário neoliberal, atendendo assim aos interesses das classes dominantes e do grande capital.

\section{PROTEÇÃO SOCIAL SOB A INFLUÊNCIA DO NEOLIBERALISMO NA DITADURA MILITAR}

Antes de seguir as análises sobre a sociedade chilena, faz-se necessário trazer elementos sobre o estado neoliberal. Para os intelectuais do neoliberalismo, os gastos sociais e o intervencionismo estatal são responsáveis pelas crises econômicas e fiscais dos estados nacionais. Assim, apresentam como solução a redução dos custos sociais e diminuição na intervenção econômica, para que o livre mercado promova a acumulação desejada. Com isso, colocam como prioridade orçamentaria dos governos a estabilidade monetária, reduzindo os investimentos com as políticas públicas e restaurando as "naturais" taxa de desemprego ${ }^{8}$, para a criação de um "exército reserva" de trabalhadores. E realizam contrarreformas ${ }^{9}$ fiscais, com incentivo ao capital externo, que significa reduzir os impostos sobre rendas e rendimentos mais altos a fim de reestabelecer a "natural" e "necessária" desigualdade. (ANDERSON, 1995).

Dessa forma, os ajustes neoliberais "tem passado pela desregulamentação dos mercados, pela redução do déficit fiscal e/ou do gasto público, por uma clara política de privatização, pela capitalização da dívida e um maior espaço para o capital internacional, inclusive como condição de empréstimos" (BERINGH, 2008, p. 65).

Nesse quadro, o Estado reduz os gastos com as políticas de proteção social, e amplia sua atuação econômica e política em prol dos interesses capitalistas. Através de forte intervenção estatal tanto na execução de contrarreformas nos direitos sociais e trabalhistas, quanto na busca por atender as demandas do capitalismo financeiro internacional.

Para as políticas sociais, o ideário neoliberal propõe a tríade: privatização, focalização e descentralização ${ }^{10}$, em que o mercado assume a execução de parte das políticas sociais que possibilita a obtenção de lucro, em especial a saúde, educação e previdência social. Já a ação das políticas, sob a responsabilidade governamental, passa a ser focalizada, principalmente na população em extrema pobreza, retirando de cena o princípio da universalização e da descentralização, não se estabelece apenas "o compartilhamento do poder entre as esferas públicas, mas como mera transferência de responsabilidades para

\footnotetext{
${ }^{8}$ Ou seja, são tomadas medidas que ocasionam o aumento das taxas de desemprego, assim essa "reserva de trabalhadores" prontos para ocupar postos no mercado de trabalho, pressiona os demais trabalhadores a aceitarem baixos salários, contratos flexíveis e outras formas de precarização do trabalho. Para ver mais consultar: ANDERSON, Perry. Balanço do neoliberalismo. In: SADER, Emir; GENTILI, Pablo (Orgs). Pósneoliberalismo: as políticas sociais e o Estado democrático. Rio de Janeiro: Paz e Terra, 1995. p. 9-23. E ANTUNES, Ricardo. Os sentidos do trabalho: Ensaio sobre a afirmação e a negação do trabalho. 6 Ed. São Paulo: Boitempo, 2002.

${ }^{9}$ Behring (2008) alerta que a utilização do termo reforma é adequado ao se referir as mudanças no Estado que levam a avanços para a classe trabalhadora, na ampliação de direitos, em especial no contexto da socialdemocracia.

10 BEHRING \& BOSCHETTI (2011)
}

Dialektiké, v. 1, 2016. p. 79-97 
entes da federação ou para instituições privadas e novas modalidades jurídicos-institucionais correlatadas" (BEHRING, BOSCHETTI, 2011, p. 156).

Na década de 1980, houve o triunfo dos conservadores ${ }^{11}$ na Inglaterra, nos Estados Unidos e na Alemanha - com a vitórias eleitorais de Margareth Thatcher em 1979, de Ronald Reagan em 1980 e de H. Kohl em 1982. Nesse contexto, o neoliberalismo ganha força na América Latina, se apresentando como "uma alternativa ao esgotamento do modelo de industrialização por substituição de importações e da ideologia desenvolvimentista, prometendo acabar com a crise da dívida externa e a alta inflação" (CASTELO, 2010, p. 21). Assim, o receituário do Consenso de Washington ${ }^{12}$ acabou sendo imposto aos países latinoamericanos, que colocaram em prática medidas como altas taxas de juros, privatização das empresas públicas, liberalização financeira e comercial, corte em gastos sociais, etc. (CASTELO, 2010, p. 21). Dessa forma, a pequena e deficitária proteção social na América Latina tem seus traços perversos acentuados "por conta dos impactos produzidos pela crise econômica e pelos ajustes neoliberais" (TAPIA, HENRIQUE, 1995, p.66).

A ditadura militar instaurada no Chile em 1973 vingou até o ano de 1990, durante todo o tempo sob o comando de Pinochet, que implementou a primeira experiência neoliberal. Seu pioneirismo fez com que as características desta forma de intervenção estatal sejam implementadas o mais próximo possível ao que era idealizado pelos órgãos de financiamento internacional (Banco Mundial, FMI, etc.), trazendo fortes impactos para as políticas sociais deste país. Além disso, também houve repressão aos movimentos sociais, privatizações, desregulação, desemprego e redistribuição de renda em favor da burguesia (ANDERSON, 1995). "O Chile de Pinochet começou seus programas de maneira dura: desregulação, desemprego massivo, repressão sindical, redistribuição de renda em favor dos ricos, privatização de bens públicos" (ANDERSON, 1995, p. 17).

Dessa forma, as políticas sociais chilenas passaram a ser operadas numa lógica de mercado, com um cunho restritivo e subordinada as metas de crescimento e estabilização da economia, focando suas ações na população em situação de extrema pobreza. Destacaremos as contrarreformas e as consequências das ações do período ditatorial para as políticas de previdência, saúde e assistência social.

\subsection{PREVIDÊNCIA SOCIAL}

\footnotetext{
11 Neste texto, entendemos como conservador o posicionamento de defesa direta ou indireta ao capitalismo, a sociedade burguesa (NETTO, 2011). Em relação ao período que retratamos Netto (2011, p. 16) afirma "que a resultante geral do giro ocorrente nos anos 1970-1980 constituiu uma impressionante onda conservadora, subjacente ao que foi chamado de 'ofensiva neoliberal' [...] Num período de poucos anos, um mundo que parecia rumar para a 'esquerda' navegou decididamente à 'direita': o pensamento conservador ganhou um fôlego aparentemente assombroso".

12 O Consenso de Washington foi uma reunião realizada em 1989, com objetivo de orientar os países da periferia do capitalismo, em relação as medidas a serem adotadas em suas adequações ao neoliberalismo, fizeram parte dessa reunião os "organismos de financiamento internacional de Bretton Woods (FMI, BID, Banco Mundial), funcionários do governo americano e economistas latino-americanos, para avaliar as reformas econômicas da América Latina [...] As recomendações dessa reunião marcaram dez áreas: disciplina fiscal, priorização dos gastos públicos, reforma tributária, liberalização financeira, regime cambial, liberalização comercial, investimento direto estrangeiro, privatização, desregulação e propriedade intelectual" (MONTAÑO, 2010, p.29).
}

Dialektiké, v. 1, 2016. p. 79-97 
A previdência social foi a primeira política de proteção social no Chile, pois ao longo do século XX "são criadas diversas caixas previdenciárias, semi-públicas, para atender alguns setores com maior poder de pressão [...] Nas caixas principais, foram criadas, em paralelo aos regimes gerais, sub-regimes preferenciais para alguns setores" (ALVIM, 2011, p.50). Até 1973, vários governos tentaram reformar o sistema previdenciário, na tentativa de unificálo, uma vez que estava organizado em diversos segmentos, distribuídos em acordo com grupos ocupacionais. As tentativas foram fracassadas, pois os diversos grupos saíam em defesa de seus direitos (MESA-LAGO; MÜLLER, 2003).

No período ditatorial, a previdência social chilena passou por uma contrarreforma, caracterizada por Mesa-lago (2003), como uma reforma estrutural - pelo radical processo de privatização, ou seja, de substituição do sistema público pelo privado - do tipo substitutiva, por fechar "o sistema público (não sendo permitidos novos filiados), substituindo-o por um sistema privado" (MESA-LAGO, 2003, p.230). Assim, o objetivo foi privatizar os fundos de pensões dos trabalhadores. Para isto, justificava-se que a previdência chilena se encontrava em déficit, era mal administrada e seus benefícios eram muito baixos, o que poderia ser alterado caso fosse privatizada.

Diante, do quadro de repressão, em 1979, mesmo com a ausência de um debate público, ocorre a unificação do sistema previdenciário chileno, "padronizando as regras de acesso e os benefícios para todos os segurados, eliminando privilégios de grupos poderosos e unificando os múltiplos esquemas anteriormente existentes" (MESA-LAGO; MÜLLER, 2003, p. 30).

Em 1980, é desmontado o modelo público, com a proibição de novas filiações, sendo substituído pelo modelo de capitalização individual, através da criação de um sistema privado e com cortes de direitos. Assim, a previdência social chilena deixou de ser administrada pelo Instituto de Normalização Previsional (INP), para ser administrado por sociedades anônimas de direito privado, as Administradoras de Fundo de Pensões (AFPs), através de contribuições individuais de caráter obrigatório apenas dos trabalhadores, pois neste sistema os empregadores não contribuem e os autônomos não são obrigados a contribuir.

As Administradoras poderiam investir os recursos dos segurados em outras atividades financeiras com o objetivo de obtenção de lucros, e no momento em que o trabalhador fosse se aposentar, ele receberia uma aposentadoria calculada através do montante acumulado, da expectativa de vida e do rendimento das ações ou títulos negociados publicamente.

O novo sistema é formado por

[...] um regime de aposentadorias de capitalização individual financiado e gerido pelo setor privado [...]. Os trabalhadores deveriam contribuir com $10 \%$ de seus salários e os fundos seriam administrados por instituições privadas denominadas Administradoras de Fundos de Pensão (AFP). Estas, por sua vez, cobrariam uma taxa incidente sobre as contribuições para arcar com seus custos administrativos e para a contratação de seguros de 
invalidez e desemprego. As contribuições dos trabalhadores eram retidas pela empresa em que trabalhavam e enviadas para suas contas previdenciárias pessoais nas AFP, escolhidas livremente pelo trabalhador (ALVIM, 2011, p.67).

Assim, buscava-se uma separação entre os benefícios oriundos das contribuições (seguros) e os da assistência social. Para tanto, baseava-se em três pilares: 1) financiado por impostos destinado a assistência social, através de dois programas, Pensões Mínimas Garantidas pelo Estado (PMGE), destinado a segurados que não conseguiam contribuir o tempo necessário (vinte anos) ou não alcançavam o saldo mínimo para aposentadoria; e o Programa de Pensões Assistenciais (PASIS), não contributivo e destinado a um número reduzido de pessoas que comprovassem não ter como suprir suas necessidades básicas; 2) o compulsório, referente as capitalizações individuais administradas pelas AFPs; 3) e contribuições voluntárias (ROBLES, 2011).

É importante destacar que se as AFPs não conseguissem sua rentabilidade mínima (ao menos $50 \%$ de retorno médio), o Estado deveria arcar com o que faltasse para garantir a liquidez e blindagem financeira das administradoras, e em caso de falência com os custos e garantir as pensões a serem pagas. Além disso, as forças armadas e a polícia permaneceram com todos os direitos garantidos e não sofreram os embates da privatização do sistema previdenciário. Assim, é explicito o investimento nas instituições privadas nesse sistema, e os custos para o setor público, bem como o retrocesso dos direitos dos trabalhadores, que não participam nem do órgão supervisor do Estado nem das AFPs, mesmo sendo os principais sujeitos interessados do processo de capitalização (ROBLES, 2011).

Ao contrário do que prometido, essas medidas trouxerem o aumento do déficit previdenciário e uma concentração no mercado das AFPs, no ano de sua implantação existiam quatorze administradoras, ao passo que em 2015 havia apenas seis. E ainda, diminui-se o número de cobertos, segundo Mesa-Lago (2008, apud, ALVIM, 2011, p.84) "em $1980,64 \%$ dos trabalhadores estavam cobertos, ao passo que em 1997 esse número cai para 57\%, em 2002 para 44\%".

Além disso, os participantes do sistema de capitalização, encontram-se em uma situação de "sub-segurados",

[...] pois o período mínimo de contribuição para garantir o direito previdenciário varia entre 10 e 30 anos. Se porventura, o segurado deixar de fazer uma contribuição mensal, o saldo registra aporte insuficiente e o benefício tende a ser baixo e restrito a um período limitado de tempo, o que acaba gerando benefícios de reduzida qualidade. Por outro lado, o estudo também revela a incapacidade do sistema de capitalização para incluir os trabalhadores que vivem relações informais e precarizadas de trabalho, e seu efeito destrutivo para a solidariedade inerente ao sistema de repartição (BOSCHETTI, 2009, p.190).

\subsection{SAÚDE}


A política de saúde até 1973 , caracteriza-se basicamente por ter os problemas sanitários sob a responsabilidade do Serviço Nacional de Saúde (SNS), instituição que tem em sua criação a contribuição da história das organizações sanitárias chilenas ${ }^{13}$. A cobertura do SNS atingia 65\% da população, tendo seus serviços direcionados aos trabalhadores e indigentes, recebendo para isso recursos estatais, das instituições privadas e dos trabalhadores, em um trabalho de saúde preventivo (básico) e curativo (médico), que "se tornou o principal centro de prática médica, de saber, de pesquisa, formação, capacitação, desenvolvimento tecnológico, absorção do pessoal de saúde e infra-estrutura sanitária, somente para exemplificar algumas de suas principais características" (TETELBOIN, 2009, p. 182-183).

Existiam também, o Serviço Médico Nacional de Empregados (Sermena), criado em 1968 , que cobria o atendimento à cerca de $20 \%$ da população, sendo um sistema misto com o objetivo de oferecer serviços privados de saúde aos empregados, recebia financiamento da previdência social (cotas de retenção) e pagamento direto dos usuários. E assistência médica privada que atendia em média $10 \%$ da população (TETELBOIN, 2009).

O processo de contrarreforma objetivou reduzir os investimentos públicos nesse setor, através do incentivo a criação de empresas privadas, as chamadas Instituições de Saúde Previsional (ISAPREs), que objetivavam sucatear os serviços públicos e ocasionar uma descentralização administrativa.

Com isso, o SNS é extinto e criado o Sistema Nacional de Serviços de Saúde (SNSS), para a integração das diversas entidades que oferecem serviços de saúde (públicas, privadas ou mistas), seguindo a lógica neoliberal de racionalização dos serviços, pois essa mudança expressou o desmonte do sistema nacional de saúde no Chile. "Não se tratou apenas de mudança de nome, mas de concepções no papel das instituições quanto à sua integralidade, programação, financiamento, carreira dos funcionários, acesso etc., e fundamentalmente, de responsabilidade com a população" (TETELBOIN, 2009, p. 194).

Em 1981, o seguro saúde foi separado da previdência, passando a existir dois tipos de sistemas de saúde: 1) público que seria responsável pelos atendimentos mais complexos e nos municípios (comunas) pelos atendimentos primários, formado pelo Fundo Nacional de Saúde (FONASA) e SNSS; 2) construído por empresas privadas que recolhiam contribuição e prestavam serviços próprios de saúde, independentes dos hospitais públicos, formado principalmente pelos ISAPREs.

A contrarreforma sofrida pela política de saúde chilena teve efeitos nocivos para a cobertura e o acesso à saúde, tendo em vista o incentivo a injeção de recursos nos setores privados em detrimento do financiamento do setor público, que passou a ofertar serviços de pouca qualidade, destinados àqueles que não poderiam acessar os serviços prestados pelo

\footnotetext{
${ }^{13}$ Segundo Tetelboin (2009, p.182) são esses: "a previdência social e as instituições sanitárias, perpetuadoras das experiências do movimento operário e seus fundos mútuos de começo do século; as experiências sanitárias do Estado na sua preocupação em projetar o desenvolvimento capital institucionalizando os esforços de cuidado sobre a força de trabalho; o saneamento ambiental; as epidemias, as catástrofes, o cuidado dos manipuladores de alimentos, a prostituição; e a existência da Beneficência e da Assistência Pública orientadas à caridade e a proteção das camadas mais pobres da sociedade".
}

Dialektiké, v. 1, 2016. p. 79-97 
mercado, uma vez que as camadas da população que detinham maior poder aquisitivo acessavam a saúde através do setor privado. "O comportamento observado nos registros do gasto público mostra uma notável diminuição. O de 1987 registra o mesmo nível de 1970. Em termos per capita, a situação de 1986-1987 registra uma queda de $30 \%$ se comparada a situação dos anos 1970 ou 1932" (TETELBOIN, 2009, p.195).

Não havia órgão fiscalizador para os ISAPREs até a redemocratização, assim tais empresas aumentavam os custos dos serviços da forma que desejavam, excluindo os pacientes de alto risco e aqueles que necessitavam de cuidados de maiores custos (idosos, grávidas, doentes crônicos, etc.) e se tornavam cada vez mais acessíveis apenas pelas camadas mais rica da população (ALVIM, 2011).

O FONASA recolhia as contribuições e repassava para os devidos sistemas (públicos ou privados). A contrarreforma aumentou os custos do sistema de saúde para a população, as contribuições passaram de $4 \%$ para $7 \%$ dos salários; os empregadores passaram a pagar uma quota de $2 \%$ para os ISAPREs para financiar a cobertura de saúde para trabalhadores com baixa remuneração (clara injeção de financiamento no sistema privado); a saída das classes mais ricas (que tinham maior contribuição) do sistema público para o privado impactou diretamente no financiamento do sistema de saúde ao ponto que em 1988 "o ISAPRE prestava serviços apenas para $11 \%$ da população, mas detinha mais da metade dos recursos provenientes das contribuições obrigatórias, e absorvia quase $45 \%$ dos gastos de saúde no país" (ALVIM, 2011, p.72).

Os indigentes e não contribuintes estão dentro da FONASA, são atendidos no sistema público e insetos da coparticipação pelos serviços prestados. O setor público também conta com empresas privadas que podem prestar determinados serviços para o Estado através da celebração de contratos. Além do setor público e do privado, também têm as seguranças mútuas, que atendem aos acidentes de trabalho e doenças relacionadas ao trabalho, e possuem suas próprias clínicas e hospitais.

Desde então, a política de saúde chilena passou por várias modificações, e até mesmo a ampliação dos seus recursos por parte do Estado, mas sua principal característica não foi alterada, continua sendo uma política mista, composta pelo setor público e pelo setor privado, que atendem diferentes segmentos sociais.

\subsection{ASSISTÊNCIA SOCIAL}

A Assistência Social seguia-se no caminho da focalização, reduziu-se os gastos públicos (de 25\% do PIB em 1970 para 15\% em 1980) em um período de altos índices de desemprego, privatizações e aumento da pobreza (ALVIM, 2011).

Para responder a tais fatores, o governo instituiu programas de transferência de renda, entre eles o Subsídio Unitário Familiar, direcionado a mães com criança em idade escolar, grávidas, e cuidadoras de idosos pertencentes a famílias pobres. E tratava-se da transferência de "US\$ 6/mês/criança e estava condicionado à comprovação da frequência escolar e acompanhamento da saúde das crianças. Estima-se que o gasto anual do programa equivalia a 0,09\% do PIB [...] e a cobertura atingia 6,3\% da população" (ALVIM, 2011, p.76). 
Mesmo com os programas de transferência de renda, a pobreza e indigência continuou a aumentar no Chile durante os anos de "chumbo".

Em 1980, Pinochet promulga uma nova constituição, legalizando seu governo ditatorial, provocando grande resistência popular. Para piorar a situação, em maio de 1983, - Chile passou por uma intensa crise fiscal (mesmo com a implementação das medidas neoliberais), aumentando ainda mais a insatisfação da população, que levou a um plebiscito popular em 1987. Em 1990, o ditador sai do poder, com a eleição do governo democrático do presidente Patricio Aylwin (1990-1994).

\title{
4 PROTEÇÃO SOCIAL APÓS A REDEMOCRATIZAÇÃO
}

No Chile, assim como no Brasil, na Argentina e no Uruguai, houve na transição da ditadura para a democracia, a resistência de setores que em seguida assumiram o poder, mas não conseguiram romper completamente com as práticas dos antigos governos. 0 máximo que se conseguiu avançar foi com o novo-desenvolvimentismo ${ }^{14}$ ou com socialliberalismo, o que não deixa de representar um avanço para o continente quando comparado com o que havia antes. (CASTELO, 2010)

\begin{abstract}
O social-liberalismo é uma proposta de revitalização do neoliberalismo por meio da adoção de uma agenda política de alívio às expressões mais agudas da "questão social". [...] Tais propostas ganham materialidade institucional por meio de políticas sociais assistenciais e focalizadas de transferência de renda, programas de economia solidária e de empoderamento dos indivíduos e comunidades e de medidas regulatórias do Estado diante das falhas do mercado. Aqui na América Latina o social-liberalismo é representativo no Chile e no Brasil, mas está presente em diversos outros países (CASTELO, 2010, p. 23).
\end{abstract}

Os governos democráticos que assumiram após o fim da ditadura militar no Chile, buscaram conciliar crescimento econômico com desenvolvimento social, focando suas ações nas camadas mais pobres da população chilena, seguindo as orientações da Comissão Econômica para a América Latina e o Caribe (Cepal), que foi criada pela Organização das Nações Unidas (ONU) após a segunda Guerra Mundial, com a função de elaborar e disseminar a teoria do desenvolvimento ${ }^{15}$ para os países da América Latina a fim de afastar a ameaça comunista e expandir a dominação imperialista.

\footnotetext{
14 Por novo-desenvolvimentismo, compreendemos o padrão de desenvolvimento capitalista, adotado após a crise dos governos neoliberais, em que se busca conciliar crescimento econômico com desenvolvimento social.

${ }^{15}$ Após a Segunda Guerra Mundial, os Estados Unidos e países do continente europeu passaram a divulgar a teoria do desenvolvimento para outros países com a finalidade de afastar a ameaça comunista da periferia do mundo capitalista e expandir a dominação econômica imperialista, tendo a Cepal (Comissão Econômica para a América Latina e Caribe) como agência de divulgação dessa teoria no continente latino-americano. Essa teoria tinha o papel de explicar o motivo pelo qual os países subdesenvolvidos encontravam-se nesse estado, e de
} 
Mas, a crise econômica que se alastrou pelos países latino-americanos e provocou estagnação, repercutiu de forma negativa nos círculos teóricos da Cepal. Assim, a partir dos anos de 1960, a Cepal modifica suas discussões, saindo do enfoque puramente desenvolvimentista e dando ênfase às reformas estruturais e à distribuição de renda como forma de intervenção nas expressões da "questão social", influenciando os países latinoamericanos (MARINI, 2010).

A Cepal, a partir dos anos de 1990, passou a defender o desenvolvimento econômico e, consequentemente, a abertura dos países latino-americanos para o mercado externo e seus interesses, ao mesmo tempo em que o Estado aumenta os investimentos em políticas sociais, com caráter compensatório e focalista (pobreza e extrema pobreza), incentivando o empreendedorismo, bem como garantindo condições necessárias para os investimentos privados que irão render "oportunidades" ao país, a partir da ampliação do mercado de trabalho (CARCANHOLO, 2010; CASTELO, 2010; 2013).

Tratado em muitos documentos como desenvolvimento com equidade, esse posicionamento tem diversos adeptos, sendo uma política que vem sendo amplamente adotada nos diversos países da América Latina. No Chile, foram realizados esforços para aumentar os gastos sociais sem que fosse comprometida a estabilidade econômica, através de um consenso firmado entre partidos políticos e principais agentes econômicos. E apesar de apresentar avanços no que se refere a redução da pobreza, não ocorrem mudanças estruturais no sistema de proteção social chileno, e as orientações neoliberais não deixaram de ser seguidas. A seguir apontaremos as principais mudanças nas políticas de previdência, saúde e assistência social.

\subsection{PREVIDÊNCIA SOCIAL}

Ao tratarmos do sistema previdenciário não houve grandes transformações, mas o modelo chileno difere de outros países, porque a capitalização da previdência é totalmente realizada por empresas privadas, não sendo apenas uma complementação ao sistema público, como acontece no Brasil

Em 2008, no Governo de Michelle Bachelet, ocorrem reformas no sistema previdenciários. Em substituição a Superintendência de AFPs foi criada a Superintendência de Pensões, para fiscalizar todo o sistema previdenciário (tanto de responsabilidade do Estado como das AFPs); o INP é substituído pelo Instituto de Previsão Social. E é instituída a Comissão de Usuários, formada por cinco representantes, um de cada segmento (trabalhador, aposentado, Instituto de Previsão Social, AFP e acadêmico, que preside a comissão) para avaliar e opinar sobre o sistema, suas reformas e estratégias (ROBLES, 2011).

Com a reforma, é notável a tentativa de articulação entre o seu pilar contributivo e não contributivo, a fim de amenizar as consequências da contrarreforma da previdência. $E$ teve três objetivos

que forma poderia haver o desenvolvimento nacional a fim de sair da situação de dependência e subdesenvolvimento. (MARINI, 2010, p.)

Dialektiké, v. 1, 2016. p. 79-97 
i) ampliar la cobertura previsional a sectores previamente excluidos; ii) incrementar y compensar la densidad de cotizaciones para aumentar las pensiones finales y disminuir la presión fiscal, junto con estimular la formalización y el ahorro previsional; y iii) reducir la desigualdad de género en la previsión social (Subsecretaría de Previsión Social, 2008) (ROBLES, 2011, p.33).

Em relação ao pilar solidário, a reforma criou três programas a fim de aumentar sua cobertura e os subsídios concedidos: 1) a Pensão Básica Solidária (PBS), trata-se de uma pensão destinada as pessoas mais pobres, maiores de 65 anos, mesmo que nunca tenham contribuído ao sistema previdenciário, com o objetivo de avançar no número dos segurados. No início, esse benefício buscava atingir $40 \%$ da população mais pobre, "siendo ampliado a $50 \%$ y proyectado para cubrir al 60\% en julio de 2012" (ROBLES, 2011, p. 34); 2) a Contribuição Previsional Solidária $\left(\right.$ APS $^{16}$ ), é uma complementação à aposentadoria contributiva oferecida pelo Estado, uma espécie de bônus para as pessoas que recebiam baixos benefícios, tem a mesmo público alvo do PBS, o valor do bônus é definido em proporção inversa ao valor que o assegurado recebe como aposentadoria, sendo suspenso quando atinge os valores máximos fixados; 3) o Bônus por Filho, todas as mães (independente da condição econômica) recebem um bônus por cada filho nascido vivo, depositado em sua conta previdenciária no dia do nascimento, no valor de $10 \%$ de dezoito salários mínimos, com a finalidade de melhorar o nível da aposentadoria da beneficiada ao completar 65 anos.

É importante ressaltar que a APS e a PBS também são consentidas por invalidez, destinado às pessoas entre 18 e 65 anos, que por algum motivo são impossibilitadas de trabalhar (por exemplo, devido alguma deficiência ou enfermidade), não têm direito a nenhum benefício do sistema de capitalização previdenciário e pertencem aos $40 \%$ da população mais pobre.

Também existe o Subsídio Previsional para os Trabalhadores Jovens, um incentivo a contratação de jovens, entre dezoito e trinta e cinco anos, sendo que por dois anos o Estado arca com 50\% das despesas previdenciárias. E o Bônus de Inverno para os idosos que recebem pensões baixas. (ROBLES, 2011; ALVIM, 2011)

No pilar contributivo, os autônomos são obrigados a contribuir. É estabelecida a obrigatoriedade da filiação ao sistema de saúde pelos usuários até 2016, sendo isentos da taxa de 7\% os beneficiários das pensões solidárias; e os Seguros de Invalidez e Sobrevivência passaram a ser concedidos por licitações da Superintendência de Pensiones, instituindo um valor único do prêmio, independente da AFP de filiação. (ROBLES, 2011; ALVIM, 2011)

E no pilar voluntário, são realizadas medidas com o objetivo de incentivar as pessoas que não possuem nenhuma atividade remunerada a contribuírem. Também se criou o Fundo de Educação Previsional, financiado pelo Estado e pelas AFPs, para divulgar e esclarecer informações sobre a previdência social. E uma política de Poupança Previsional Voluntária $\left(\mathrm{APV}^{17}\right)$, que visa complementar as aposentadorias dos trabalhadores, através de

\footnotetext{
${ }^{16}$ A sigla vem da escrita do benefício em seu idioma de origem, o espanhol: Aporte Presivional Solidario (APS).

${ }^{17}$ A sigla da escrita em seu idioma de origem, o espanhol: Ahorro Presivional Voluntario (APV).
}

Dialektiké, v. 1, 2016. p. 79-97 
um processo coletivo, por meio de contratos entre os empregadores e as AFPs, para depositar valores acordados com os trabalhadores. Além disso, instituiu-se medidas regulatórias para diminuir os custos administrativos das AFPs.

O modelo chileno é inspiração para a contrarreforma do sistema previdenciário de vários países, entre eles Estados Unidos e Brasil. (ROBLES, 2011).

\subsection{SAÚDE}

Na transição democrática, a saúde foi uma das maiores pautas de negociação, pois as medidas de Pinochet foram muito danosas para esse setor. Nos governos democráticos aumenta-se as verbas para a saúde pública, "[...] entre 1995 e 2005, o gasto público com saúde quase quadruplicou no Chile" (ALVIM, 2011, p.74). Entre outras providências tomadas, destacamos a criação, em 1995, da Superintendência dos ISAPRES, para supervisionar e regular essas empresas privadas. E em 2002, o Estado assumiu os custos da licença maternidade, independente da renda ou seguradora.

Em 2004 houve uma importante reforma na política de saúde pública, a fim de reduzir as disparidades existentes entre os grupos de diferentes níveis socioeconômicos que acessam os serviços de saúde no país, assim como melhorar a questão do financiamento da política e a utilização dos recursos. Para tanto, o Ministério da Saúde foi fortalecido e também foi criada a Superintendência da Saúde (absorve a Superintendência dos ISAPRES), para unificar o monitoramento e controle.

Como formas de aumento e melhoria no acesso à saúde, tem-se a vacinação gratuita contra gripe, consultas gratuitas sobre cuidados básicos por um sistema telefônico, serviços emergenciais, concessão de subsídio para gastos com água potável e esgoto.

O FONASA passa a conceder recursos, priorizando os municípios mais pobres, a fim de diminuir as desigualdades em relação à saúde, e cria o Acesso Universal com Garantias Explícitas em Saúde (AUGE), trata-se de um plano para garantia de serviços de saúde aos membros do FONASA e ISAPRES, como cuidados com o parto. Ainda existem outras medidas tramitando nas esferas da governança.

\subsection{ASSISTÊNCIA SOCIAL}

Em relação a assistência social, no governo de Patricio Aylwin (1990-1994), houve um maior compromisso com o investimento nas políticas sociais, sendo progressivamente crescente o montante de recursos destinados à população em situação de extrema pobreza, através do Fundo de Solidariedade e Investimento Social (FOSIS).

O FOSIS consiste em um fundo público que financia atividades e projetos de desenvolvimento social, voltados para comunidades e territórios que possuem um alto índice de pobreza e desigualdade social. Desde 2000, foi montado um conjunto de programas sociais que visam proteger as famílias, assim como também assegurar os mínimos sociais para pessoas em diferentes etapas do ciclo de vida. 
A Rede de Proteção Social "Protege" conta com nove programas sociais interligados, nos quais seis são destinados a famílias em situação de pobreza, extrema pobreza e a situações de vulnerabilidade social, relacionadas aos diferentes momentos do ciclo de vida: Chile Cresce Contigo, Bolsas de Estudo, Subsídio para Contratação de Jovens, Subsídios de Habitação, Pensão Básica Solidária e Chile Solidário. E três são de acesso universal: Seguro Desemprego, Bônus por Filho e o Plano de Acesso Único de Garantias Explícitas (ROBLES, 2011). Dessa forma, a assistência social chilena é formada por uma rede de programas sociais e por uma articulação com as demais políticas.

O Programa Chile Solidário tornou-se política de Estado após aprovação da Lei no 19.949 em maio de 2004 e, com coordenação nacional do Ministério do Desenvolvimento Social, constitui-se como o principal programa da assistência social, promovendo transferências monetárias não contributivas através da oferta de serviços exclusivos, além de subsídios que dão acesso à coparticipação para as outras políticas sociais, como saúde, educação e habitação, através de uma articulação entre a política de assistência social e as demais políticas sociais, pois as ações do "Protege" engloba vários ministérios. E a permanência do usuário no programa é de, no máximo, cinco anos.

O programa Chile Solidário conta com um sistema de informação para definição de critérios para seleção de beneficiários. Este programa tem quatro princípios básicos: apoio psicossocial às famílias beneficiárias, direcionadas pelo programa Ponte, que é feito por profissionais no período de dois anos, para reorganizar o sistema familiar e encaminhar a família para outras redes que oferecem atendimento especializado; proteção imediata à família; garantia de subsídios em dinheiro, pago a cada seis meses durante dois anos de acompanhamento da família; e acesso preferencial aos programas de promoção social, emprego e previdenciários (ROBLES, 2011). Durante o período de apoio à família, o programa garante uma transferência em dinheiro, "bônus de proteção", que não visa complementar a renda familiar, mas cobrir os custos de transação envolvidos no acesso a outros serviços sociais.

Os beneficiários do Chile Solidário têm acesso a uma série de benefícios que consistem em subvenções, subsídios e títulos não-contributivos, alguns dos quais já estavam em funcionamento antes da formação deste sistema. Além dos bônus e benefícios, o Chile Solidário promove uma série de acordos com organismos públicos para garantir o acesso prioritário dos beneficiários aos seus programas e, em vários casos, para criar oferta específica para este grupo. Esse programa tem cobertura nacional, mas é executado pelos municípios através das Unidades de Intervenção Familiar.

As famílias do Chile Solidário podem acessar ainda aos seguintes subsídios monetários: Subsídio Único Familiar (SUF), Subsídio de Incapacidade Mental, Subsídio Cédula de Identidade, Subsídio Preferencial e Pro-Retenção Escolar, Subsídio para o Consumo de Água Potável e Serviço de Redes de Esgoto (SAP) e Pensão Básica Solidária. E também busca firmar convênios com uma série de organismos públicos para garantir acesso prioritário de seus usuários a programas de acesso a emprego, saúde, educação e habitação.

Desde 1979, o principal instrumento utilizado para selecionar os beneficiários da política de assistência social era a Ficha CAS, que era preenchida pelos municípios. Esta ficha sofreu várias alterações durante esses anos, mas sempre mantendo como eixos de avaliação as condições de moradia, educação, trabalho, renda e patrimônio das famílias. Através dessa 
ficha foi criado o índice CAS, e a partir da pontuação obtida, era decidido se a família iria ou não acessar a política.

Em 2006, a Ficha CAS passa por um processo de reformulação com vistas a buscar uma melhor forma de selecionar as famílias beneficiárias, dando lugar a Ficha Proteção Social, que tem como foco a família como unidade de análise. Agora além das variáveis existentes da ficha anterior, estão sendo levadas em conta a estrutura familiar, os riscos individuais e do território. A atual ficha cobre $65 \%$ da população do país, dando possibilidade para a seleção em diversos programas sociais.

\section{CONDIDERAÇÕES FINAIS}

O Chile foi um dos países da América Latina que primeiro implementou um sistema de proteção social, no ano de 1921. E entre os governos de 1958 e 1973 é notável o esforço para realizar reformas com o objetivo de desenvolver seu sistema de proteção social. Mas, com a instauração da ditadura militar (1973-1990), há um rompimento desse processo, com a implementação do ideário neoliberal no país.

Dessa forma, para entender a construção e o atual modelo de proteção social chileno, se fez necessário contextualizar a lógica imposta à intervenção do Estado durante a ditadura de Pinochet. Pois, neste período, as políticas sociais foram reestruturadas de acordo com o ideário neoliberal, que trouxe consequências danosas para seus desenvolvimentos.

Por mais ou menos 20 anos, o neoliberalismo foi o modelo de integração subordinada da América Latina à nova fase imperialista do grande capital, reafirmando o caráter espoliativo, dependente e iníquo do modo de produção capitalista na região (CASTELO, 2010, p. 22).

Assim, ao fim da ditadura militar, em 1990, a desigualdade social no país encontrava-se em níveis elevados. Contudo, os governos democráticos não abandonaram por completo o ideário neoliberal, seguindo com o modelo social-liberal, na busca por conciliar crescimento econômico com maiores investimentos nas políticas que compõem a proteção social no país.

As políticas sociais no Chile atualmente adquiriram um caráter progressivo, o que tem proporcionado ao país maior desenvolvimento social, que possui o maior Índice de Desenvolvimento Humano (IDH) da América Latina $(0,822)$ estando na 41a colocação mundial, segundo o ranking de 2013, e sendo o único país latino-americano a fazer parte da Organização para Cooperação e Desenvolvimento Econômico (OCDE).

Porém, é importante ressaltar que as reformas realizadas nas políticas sociais durante os governos democráticos (sucessores da ditadura militar) não objetivaram reestruturar essas políticas, mas sim amenizar os nefastos resultados da contrarreforma executadas no período ditatorial. Com isso, apesar dos bons indicadores de IDH, o Chile é um 
dos países mais desiguais da América Latina, e possui o pior índice de desigualdade dos países que fazem parte da $O C D E,(0,51)$, conforme o coeficiente de Gini.

Vale ressaltar ainda que, desde 2011, o país tem passado por uma onda de protestos em decorrências da insatisfação com lógica privatista das políticas sociais, como é o caso da educação superior, além das demais já citadas ao longo do artigo.

Ao analisarmos o panorama dos governos pós-redemocratização, é notável o desenvolvimento de uma política caracterizada como "novodesenvolvimentista" (CASTELO, 2010; 2013;). Porém, atualmente tem-se um processo de esgotamento do ciclo "neodesenvolvimentista" na América Latina, seja pelas mobilizações populares movidas pelo descontentamento com os serviços prestados pelas políticas públicas ou nas crises econômicas enfrentadas por diversos países dessa região (em alguns lugares culminando na ascensão de governos conservadores).

\section{REFERÊNCIAS}

ALVIM, Renata Baía Afonso Rego. Seguridade social na América Latina: trajetórias recentes de reforma e contrarreforma. 2011. 217f. Dissertação (Mestrado em Economia) Universidade Federal do Rio de Janeiro, Rio de Janeiro. 2011.

ANDERSON, Perry. Balanço do neoliberalismo. In: SADER, Emir; GENTILI, Pablo (Orgs). Pósneoliberalismo: as políticas sociais e o Estado democrático. Rio de Janeiro: Paz e Terra, 1995. p. 9-23.

ANTUNES, Ricardo. Os sentidos do trabalho: Ensaio sobre a afirmação e a negação do trabalho. 6 ed. São Paulo: Boitempo, 2002.

BEHRING, Elaine Rossetti. Brasil em contra-reforma: desestruturação do Estado e perda de direitos. 2 ed. São Paulo: Cortez,2008.

BEHRING, Elaine Rossetti; BOSCHETTI, Ivanete. Política social: fundamentos e história. 9. ed. São Paulo: Cortez, 2011.

BOSCHETTI, Ivanete. A Insidiosa Corrosão dos Sistemas de Proteção Social Europeus. Serviço Social e Sociedade, São Paulo, n. 112, p. 754-803. 2012

BOSCHETTI, Ivanete. A seguridade social na América Latina. In: BOSCHETTI, Ivanete; BEHRING, Elaine Rossetti; SANTOS, Silvana Mara de Morais dos; MIOTO, Célia Regina Tamoso (Orgs). Política Social no capitalismo: tendências contemporâneas. 2 ed. São Paulo: Cortez, 2009.

CARCANHOLO, Marcelo. Neoconservadorismo com roupagens alternativas: a nova Cepal dentro do Consenso de Washington. In: CASTELO, Rodrigo (Org.). Encruzilhadas na América Latina no século XXI. Rio de Janeiro: Pão e Rosas, 2010. p. 191-211. 
CASTELO, Rodrigo. O novo desenvolvimentismo e a decadência ideológica do estruturalismo latino-americano. In: CASTELO, Rodrigo (Org.). Encruzilhadas na América Latina no século XXI. Rio de Janeiro: Pão e Rosas, 2010.

CASTELO, Rodrigo. $\mathbf{O}$ social-liberalismo: auge e crise da supremacia burguesa na era neoliberal. São Paulo: Expressão Popular, 2013.

CASTRO, Manuel Manrique. História do Serviço Social na América Latina.7 ed. São Paulo: Cortez, 2006.

COOPERACIÓN DESCENTRALIZADA FRANCE-AMÉRICA DEL SUR. Organização políticoadministrativa no Chile. [S.I.]. Disponível em :

<http://www.franceamsud.org/observatorio/index.php/pt/chile>. Acesso em: 22 de jun de 2015.

BEHRING, Elaine Rossetti; BOSCHETTI, Ivanete. Política Social: fundamentos e história. 9 ed. São Paulo: Cortez, 2011.

FERNANDES, Daniela. OCDE: desigualdade aumenta em países ricos, mas cai na América Latina. BBC Brasil. Paris, 21 de mai de 2015. Disponível em: < http://rizomas.net/culturaescolar/bases-de-dados/208-regras-para-citacao-e-referencias-abnt.html >. Acesso: 28 de jun. de 2015.

MANZANO, Sofia. Economia política para trabalhadores. São Paulo: ICP, 2013.

MARINI, Rui Mauro. A crise do desenvolvimentismo. In: CASTELO, Rodrigo (Org.). Encruzilhadas da América Latina no Século XXI. Rio de Janeiro: Pão e Rosas, 2010. p. 103118.

MARX, Karl; ENGELS, Friedrich. Manifesto Comunista. São Paulo: Boitempo, 2014. MESA-LAGO, Carmela; Müller, Katharina. Política e reforma da previdência na América Latina. In: COELHO, Vera Schattan P. (Org.). A reforma da previdência na América Latina. Rio de Janeiro: Editora FGV, 2003. p. 27-64.

MESA-LAGO, Carmela. A reforma estrutural dos benefícios de seguridade social na América Latina: modelos, características, resultados e lições. In: COELHO, Vera Schattan P. (Org.). A reforma da previdência na América Latina. Rio de Janeiro: Editora FGV, 2003. p. 227-259.

MONTAÑO, Carlos. Terceiro setor e questão social: Crítica ao padrão emergente de intervenção social. 6 ed. São Paulo: Cortez, 2010.

NETTO, Leila Escorsim. O conservadorismo clássico: elementos de uma caracterização e crítica. São Paulo: Cortez, 2011. 
OLIVEIRA, Augusto Neftali Corte de. Partidos e política social no Brasil e no Chile: PT e PS nas eleições e no governo. Revista Debates, Porto Alegre, v.3, n.2, p.39-67, jul/dez. 2009.

Disponível em: < http://seer.ufrgs.br/index. php/debates/article/view/10904/6847>. Acesso em: 02 de jun de 2015.

PONTIFÍCIA UNIVERSIDADE CATÓLICA DE SÃO PAULO; UNIVERSIDAD DE LA HABANA; UNIVERSIDAD ARCIS E ASSOCIAÇÃO BRASILEIRA DE ECONOMIA DA SAÚDE. Políticas sociais em Cuba, Chile e Brasil. In: SEMINÁRIO DE ECONOMIA E SAÚDE, 2014, São Paulo. Anais eletrônicos. 2014. São Paulo: Novotel-Jaraguá, 2014 Disponível em: < http://abresbrasil.org.br/sites/default/files/politicas_sociais_em_cuba_chile_e_brasil.pdf>. Acesso em: 28 de mai de 2015.

ROBLES. Claudia. El sistema de protección social de Chile: Una mirada desde la igualdad. Santiago: Comisión Económica para América Latina y el Caribe, 2011. Disponível em: <http://repositorio.cepal.org/bitstream/handle/11362/3907/S1100694.pdf?sequence=1>. Acesso em 21 de jun de 2015.

SANTOS, Josiane Soares. Particularidades da questão social no Brasil: mediações para seu debate no governo Lula. Serv. Soc. Soc., São Paulo, n. 111, p. 430-449, jul./set. 201 SANTOS, Josiane Soares. Questão social: particularidades no Brasil. São Paulo: Cortez, 2012.

SILVA, Maria Ozanira da Silva. Caracterização e problematização dos Programas de Transferência de Renda Condicionada (PTRC) na América Latina e Caribe. In: SILVA, Maria Ozanira da Silva (Coord.). Programas de Transferência de Renda na América Latina e Caribe. São Paulo: Cortez, 2014. p. 85-234.

TAPIA, Jorge R. B.; HENRIQUE, Wilnês. Crise, reforma e políticas sociais na América Latina. Revista São Paulo em Perspectiva, São Paulo, v.09, n.1, p. 66-72, jan/mar. 1995. Disponível em: <http://produtos.seade.gov.br/produtos/spp/v09n01/v09n01_21.pdf>. Acesso em: 13 de nov. de 2015.

TETELBOIN, Carolina. Chile: políticas neoliberais e saúde. In: LAURELL, Asa Cristina (Org.). Chile: políticas Neoliberais e Saúde. 5 ed. São Paulo: Cortez, 2009. p. 179-200. 